
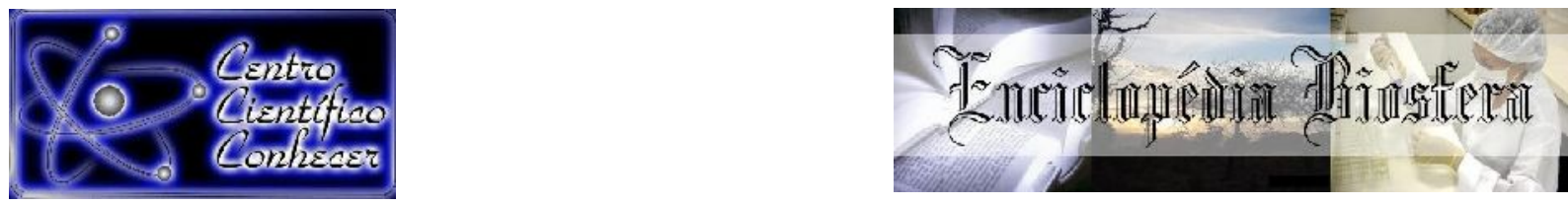

\title{
COLEÇÃO DIDÁTICA DE INSETOS COMO FERRAMENTA PEDAGÓGICA NO ENSINO MÉDIO TÉCNICO EM AGROPECUÁRIA
}

Rafael Roberto Dallegrave Negretti ${ }^{1}$, Adriana Maria da Silva Costa ${ }^{2}$, Caroline Aparecida Vitoria da Costa ${ }^{3}$

${ }^{1}$ Professor do Instituto Federal de Educação Ciência e Tecnologia do Rio Grande do Sul, Campus Vacaria-RS. E-mail: rafael.negretti@vacaria.ifrs.edu.br

${ }^{2}$ Professora do Centro Universitário Internacional - UNINTER, Vacaria-RS.

${ }^{3}$ Aluna do Curso Técnico em Agropecuária Integrado ao Ensino Médio Instituto Federal de Educação Ciência e Tecnologia do Rio Grande do Sul, Campus Vacaria-RS.

\section{Recebido em: 15/11/2021 - Aprovado em: 15/12/2021 - Publicado em: 30/12/2021 DOI: 10.18677/EnciBio_2021D16}

trabalho licenciado sob licença Creative Commons Attribution-NonCommercial-NoDerivatives 4.0 International License.

\begin{abstract}
RESUMO
A busca por novas metodologias e ações didáticas, que contribuam de forma efetiva para o aprendizado dos alunos, é um desafio constante nas instituições de ensino e no dia a dia do professor em sala de aula. De que forma tornar cada vez mais relevante a abordagem de diferentes conteúdos, tornando as aulas atrativas e significativas para o aluno? Diante desse questionamento, o presente artigo busca apresentar uma análise acerca do uso de uma coleção didática de insetos como ferramenta pedagógica, para alunos do $1^{\circ}$ ano do curso Técnico Agropecuária Integrado ao ensino médio do IFRS Campus Vacaria. Atrelou-se aulas teóricas e práticas, abordando etapas de secagem, montagem e identificação de insetos, tendo, como resultado final, a confecção da caixa entomológica. Constatou-se, durante todo processo, a interação e a troca de conhecimentos entre alunos, caracterizando-se como uma aprendizagem cooperativa. Portanto, trabalhar de forma colaborativa atrelando a teoria e prática propiciou aos alunos resultados positivos no processo de ensino e aprendizagem, pois, a coleção didática de insetos como ferramenta pedagógica possibilitou aos alunos associar seus conhecimentos cotidianos e científicos, oportunizando momentos de questionamentos e trocas de experiências referentes ao objeto de estudo.
\end{abstract}

PALAVRAS-CHAVE: Aulas práticas, Coleção entomológica; Métodos de ensino.

\section{DIDACTIC COLLECTION OF INSECTS AS A PEDAGOGICAL TOOL IN TECHNICAL SECONDARY EDUCATION IN AGRICULTURE}

\begin{abstract}
The search for new methodologies and didactic actions that contribute effectively to students' learning is a constant challenge in educational institutions and in the teacher's daily routine in the classroom. How to form to make the approach of different contents increasingly relevant, making the classes attractive and meaningful to the student? In view of this questioning, the aforementioned article seeks to present an analysis of the use of a didactic collection of insects as a pedagogical tool, for students of the 1st year
\end{abstract}


of the Agricultural Technical Course Integrated to IFRS Campus Vacaria. Theoretical and practical classes were tackled, covering drying, assembly and identification steps, with the final result of making the entomological box. Throughout the process, interaction and the exchange of knowledge between students were characterized as cooperative learning. Therefore, working collaboratively linking theory and practice provided students with positive results in the teaching-learning process, as the didactic collection of insects as a pedagogical tool enabled student to associate their daily and scientific knowledge, providing opportunities for questions and exchanging experiences related to the object of study.

KEYWORDS: Entomological collection; Practical classes; Teaching methods.

\section{INTRODUÇÃO}

A utilização de recursos didáticos não convencionais em consonância com os tradicionais vem contribuindo para uma maior interação no processo de ensino e aprendizagem. Uma das alternativas mais viáveis para a substituição dos paradigmas didáticos é a utilização de laboratórios e materiais práticos diversos, que, além de incorporar outras dimensões ao ensino, favorecem e ampliam a relação entre alunos e professores (ALBUQUERQUE et al., 2014; GUIMARAES-BRASIL et al., 2017). Nesse processo de quebra de paradigma na relação entre professor e aluno, o professor deve assumir o papel de mediador, buscando, com auxílio de diferentes materiais didáticos, proporcionar um aproveitamento positivo durante 0 andamento da disciplina $e$ conteúdos abordados por ele.

Para que as ferramentas pedagógicas desempenhem seu papel, faz-se necessário o esforço coletivo e a disponibilidade de experienciar novas metodologias, por parte de todos os envolvidos no processo de ensino e aprendizagem, considerando que o conhecimento é uma construção social e deve ser feita coletivamente. Nesse contexto, entre as várias possibilidades práticas, encontram-se as coleções entomológicas compostas por materiais biológicos (insetos inteiros ou partes deles) adequadamente tratados, conservados, organizados e sistematizados (CAMARGO et al., 2015).

Quando é abordada a utilização de coleções didáticas como ferramenta pedagógica, faz-se necessário trabalhar com o seu conceito, tendo como base o que salienta Moya (1998), indicando que as coleções são as principais ferramentas nas quais se baseiam as exposições em museus e os programas educativos. Elas incluem os objetos de importância "estética, histórica, educativa ou científica". De forma geral, uma coleção didática torna-se material destinado ao ensino, demonstrações e treinamento, em que o aprendizado é mais efetivo e imediato.

Trazendo essa ferramenta para o estudo da entomologia, ela possibilita o contato direto e demonstrações aos alunos e profissionais que estudam os insetos. A prática de coleta e produção dessas caixas utilizadas para depósito e manuseio dos insetos sempre desperta um maior interesse dos estudantes. É uma ferramenta altamente acessível devido ao baixo custo de produção, que, além de prender a atenção dos alunos, devido ao seu elevado potencial de atratividade, contribui para a desconstrução de paradigmas maléficos associados à maioria dos insetos (SANTOS; SOUTO, 2011).

Vale ressaltar que a coleção entomológica pode atuar facilitando a aprendizagem dos alunos, tendo em vista que, a partir de sua utilização, torna-se possível apresentar, de maneira tátil, a classificação, morfologia e diferentes fases do ciclo de vida dos insetos, possibilitando a interação entre as capacidades motoras e sensoriais dos 
alunos (GULLAN; CRANSTON, 2010). A montagem de coleções entomológicas em escolas ampara a aprendizagem dos alunos, fazendo com que desconstruam mitos e construam uma visão crítica sobre o tema para uma melhor acomodação do conhecimento. Segundo Santos e Souto (2011), no momento em que os alunos entram em contato direto com o objeto de estudo, o ambiente escolar e a aula tornam-se atrativos e instigantes, desmitificando o papel do aluno unicamente com receptor passivo de informações, ele passa fazer parte da construção efetiva do ensino aprendizagem.

Como salienta Godotti e Ramão (1998), o aluno aprende quando ele torna-se sujeito de sua aprendizagem, ele precisa participar das decisões que dizem respeito ao projeto da escola. Esse projeto é inserido no projeto de vida do próprio aluno. Não há educação e aprendizagem sem sujeito da educação e da aprendizagem. A participação pertence à própria natureza do ato pedagógico.

Pode-se dizer que 0 ato pedagógico somente se solidifica com a participação efetiva de todos os agentes do processo. Nesse contexto, como abordam Albuquerque et al. (2014), atividades práticas, como a coleta de insetos, contribuem com o interesse e aprendizagem dos alunos, principalmente, em temáticas de cunho científico, cuja metodologia de trabalho está inserida nas escolas de ensino profissional. Ainda segundo Seniciato e Cavassan (2004), as aulas desenvolvidas em ambientes naturais têm se apresentado como eficazes, pois oportunizam aos alunos envolvimento nas atividades educativas e constituem um instrumento importante de superação e construção do conhecimento. Já atividades em laboratório, como classificação taxonômica usando bibliografia, facilita a organização da informação e, neste caso, o descobrimento da ordem que pertence determinado inseto. Nesse processo de descoberta e pesquisa, o professor atua como mediador, encaminhando as atividades, proporcionando aos alunos uma formação integral.

Os insetos, em coleções didáticas, desempenham um papel de extrema relevância para o ensino formal de ciências e representam um grande acervo científico regional, pois o conhecimento atrelado em uma coleção biológica traz impactos positivos para biólogos, zoólogos, entomólogos, pesquisadores nas áreas agronômica e agricultores, que podem beneficiar-se da correta identificação de pragas agrícolas (CAMARGO et al., 2015), além de auxiliar na educação ambiental de jovens (JURBERG, 2005). Dessa forma, coletar, montar e preservar insetos é uma excelente maneira de aprender sobre eles (AZEVEDO et al., 2012), sendo de suma importância para o estudo da biodiversidade e biogeografia regional (SOUSA-LOPES, 2017).

Considerando a coleção de insetos com recurso pedagógico essencial ao ensino do técnico em agropecuária e a necessidade de realizar atividades a campo, que despertem o interesse sobre o tema, além de oportunizar acesso e visualização física ao material, esse trabalho visa propiciar ao aluno, por meio da prática, coletar, classificar e confeccionar uma caixa entomológica para construção de uma coleção didática. Esse material, após o término da disciplina, ficará à disposição da instituição de ensino e comunidade para pesquisa e conhecimentos, junto ao laboratório didático de Fitossanidade do IFRS Campus Vacaria.

\section{RELATO DE CASO}

A coleção foi organizada por alunos dos $1^{\circ}$ anos do curso Técnico Agropecuária Integrado ao ensino médio do Instituto Federal de Ciência Educação e Tecnologia do 
Rio grande do Sul (IFRS) - Campus Vacaria - RS e por estagiários e bolsistas do Laboratório didático Fitossanidade (LABFITO) do Campus, onde a coleção permanece armazenada e conservada. As atividades ocorreram durante a disciplina Fitossanidade e Agroclimatologia do curso, envolvendo o total de 93 alunos, no período de fevereiro de 2017 até dezembro de 2019.

As atividades de coleta estavam amparadas pela licença de autorização com finalidade didática e científica no âmbito do ensino, número 62310-1 fornecido pelo Sistema de Autorização e Informação em Biodiversidade - SISBIO. As ações foram realizadas através de aulas práticas, na mata, em lavouras de culturas anuais, hortas e pomares próximos ao Campus do IFRS Vacaria. Para completar a caixa de insetos, os alunos realizaram coletas em suas residências nas cidades de Muitos Capões, Monte Alegre dos Campos, Esmeralda, Bom Jesus, Ipê e Vacaria. Os insetos foram coletados manualmente ou com auxílio de instrumentos de coleta apropriados, como pinças, pano de batida, rede entomológica e armadilhas noturnas com fontes de luz que atraem insetos. Em todas as coletas, os estudantes conduziam um recipiente plástico para acondicionar os insetos coletados.

Após a coleta, os insetos foram trazidos ao laboratório de fitossanidade, sacrificados em câmara mortífera, utilizando acetona, e transferidos para frascos plásticos. Em seguida, iniciou-se o processo de montagem através da alfinetagem, utilizando alfinetes entomológicos em suporte de isopor e colocados em estufa artesanal, confeccionada pelos alunos bolsistas do laboratório, a uma temperatura média de $40^{\circ} \mathrm{C}$ por um período de 48 a 72 horas para secagem.

Num segundo momento da prática, deu-se início à identificação dos insetos, trabalho coletivo entre alunos e professor. Orientados pelo professor da disciplina, os alunos formaram grupos de três a quatro pessoas e, com auxílio de chaves de identificação simplificadas e manuais bibliográficos, identificaram cada inseto de acordo com as orientações estudadas em sala. Ocorreu ajuda mútua entre os alunos, para que cada um conseguisse identificar os insetos da sua caixa. $\mathrm{Na}$ sequência, os insetos eram devidamente etiquetados com as seguintes informações: ordem a que o inseto pertence, coletor, local e data da coleta. Por fim, agrupados em ordem e acondicionados em caixas para serem entregues ao professor como atividade prática avaliativa da disciplina de fitossanidade.

Os alunos montaram suas próprias caixas com 20 insetos de diferentes ordens. As caixas utilizadas pelos alunos eram de baixo custo e fácil aquisição, como as de papelão utilizadas na compra de calçados ou camisas. Cada aluno matriculado na disciplina de fitossanidade realizava todos os procedimentos desde a coleta dos insetos até a montagem final da sua própria caixa entomológica. Os alunos preparavam-nas para acondicionar os insetos colocando isopor no fundo e, por fim, revestindo com tecido TNT branco. Todas as etapas foram acompanhadas pelo docente responsável pela disciplina juntamente com os bolsistas e os estagiários do laboratório de fitossanidade.

Como última atividade da disciplina, os alunos tiveram, na forma de seminário, um momento de apresentar o resultado final do seu trabalho, a caixa de insetos e socializar a experiência vivida durante as aulas. As caixas foram entregues aos cuidados do laboratório de fitossanidade para conservação do material. Os bolsistas do laboratório realizaram o acondicionamento em armário entomológico com a temperatura controlada de $18^{\circ} \mathrm{C}$, devidamente classificados por ordens e famílias. A coleção, atualmente, 
encontra-se em estado de conservação e armazenada no laboratório de fitossanidade estando à disposição de toda comunidade.

\section{RESULTADOS E DISCUSSÃO}

No período de fevereiro de 2017 a dezembro de 2019, 93 alunos pertencentes a três turmas do $1^{\circ}$ ano do curso Técnico Agropecuária do IFRS Campus Vacaria, matriculados na disciplina de fitossanidade, realizaram 12 aulas práticas com saídas a campo para coletar insetos (Conforme descrito no quadro 1). Essas atividades foram de suma importância, proporcionando aos alunos estarem em contato direto com o objeto de estudo, tirando as dúvidas em tempo real e revendo novos conceitos referentes ao modo de pensar e compreender os insetos. É importante destacar que as aulas práticas externas à sala de aula despertam mais curiosidade sobre os temas, além de serem divertidas e propiciar interação entre a turma.

QUADRO 1. Práticas a campo, práticas no laboratório, caixas entomológicas confeccionadas e quantidades de insetos na coleção do Laboratório de Fitossanidade IFRS - Campus Vacaria, 2021.

\begin{tabular}{|l|c|}
\hline \multicolumn{1}{|c|}{ Atividades } & Resultado das atividades \\
\hline Práticas de campo realizadas & 12 \\
\hline Práticas de laboratório realizadas & 09 \\
\hline Caixas entomológicas confeccionadas & 93 \\
\hline Total de insetos na coleção & 1203 \\
\hline
\end{tabular}

Fonte: Laboratório de Fitossanidade - Labfito.

Segundo Matos et al. (2009), o uso de metodologias alternativas para o ensino deve ser estimulado nas instituições como uma forma de incentivar a participação dos alunos no processo de aprendizagem, bem como promover a integração entre conteúdo, desenvolvimento de aulas práticas e intercâmbio entre os alunos através da troca e conhecimento, criatividade e espírito de equipe.

A aula prática permite ao professor sair do formato do livro didático e adaptar à realidade de cada escola e de cada especificidade de ensino. Quando o aluno associa o conteúdo com o seu dia a dia durante a interpretação de textos fica mais fácil absorver e colocar em prática o conhecimento. Conforme Krasilchick (2005), o aluno observa a teoria em sala e a aula prática confere-lhe significados próprios, pois a aula em que apenas se repassa conteúdo, denominada tradicional, não desenvolve no aluno o senso crítico, constituindo-se em instrução e treinamento.

Dessa forma, para que, de fato, ocorra a aprendizagem, deve ser proporcionado ao aluno questionar a realidade, formulando problemas e tratando de resolvê-los, utilizando-se, para isso, o pensamento lógico, criatividade, intuição, capacidade de análise crítica, selecionando procedimentos e verificando sua adequação (BRASIL, 1998). Considerando o exposto, os alunos foram envolvidos em todas as fases de desenvolvimento do trabalho, participando ativamente de todo o processo.

A coleta, a montagem e a identificação dos insetos permitiram a cada um dos estudantes a possibilidade de classificação taxonômica dos próprios insetos coletados. Para ocorrência da aprendizagem significativa, é importante o uso de materiais ou tarefas que sejam potencialmente significativos (MOREIRA, 1999). Segundo Moram 
(2000), não se pode dar aula da mesma forma para alunos diferentes, para grupos com diferentes motivações. Precisa-se adaptar a metodologia a técnicas de comunicação a cada grupo.

Há alunos que estão prontos para aprender, abertos à troca e novas aprendizagens, fato que dá maior abertura para trabalhar diferentes metodologias durante as disciplinas, esses alunos juntamente com o professor podem tornar-se entusiastas da disciplina e pesquisa, motivando toda a turma, possibilitando a todos alcançar, ao final da disciplina, resultados significativos na aprendizagem de todos. Conforme Moran (2000), alguns alunos, no início do curso, podem estar distantes, mas sabendo chegar até eles, mostrando abertos, confiantes e motivadores, sensibilizando-os para o que eles vão aprender no curso, eles respondem bem e dispõem-se a participar.

Durante o período de três anos, 93 caixas entomológicas foram confeccionadas pelos estudantes (quadro 1). Essas caixas contribuíram para facilitar o ensino sobre a classificação dos insetos, anatomia, hábitos alimentares através da diferenciação dos diferentes tipos de aparelho bucal, identificação de pragas de culturas agrícolas e insetos benéficos que realizam o controle biológico. Essa vivência prática na construção de insetários aproxima o aluno da realidade agrícola local, fazendo com que ele tenha compreensão maior dos problemas e benefícios que os insetos podem ocasionar à agricultura. Segundo Santos e Souto (2011), a montagem de coleções entomológicas em escolas auxilia no aprendizado dos alunos, fazendo com que derrubem mitos e construam uma visão crítica sobre o tema. Para Guimarães-Brasil et al., (2017), para transpor a barreira do medo, muitos alunos necessitam do apoio e incentivo dos colegas do grupo para realizarem coletas de insetos e outras atividades. Outro benefício no processo de coleta e catalogação de espécime foi a troca de conhecimentos entre os educandos, o que, segundo Barbosa e Jófilli (2004), é o princípio básico fundador de uma aprendizagem cooperativa.

A união desses dois pontos em uma investigação a campo (aula de campo) com o auxílio e colaboração entre colegas é o princípio norteador de uma aprendizagem cooperativa e significativa. Facilitando a assimilação do conhecimento por parte dos educandos, esse modelo de aprendizagem vem tendo mais adesão a cada dia por apresentar uma troca de conhecimento entre os participantes. Quando o educando por si só realiza uma atividade, a qual finaliza com um material concreto que ele possa ver e tocar com ajuda do outro, ele pode ver de forma não abstrata o conhecimento construído por ele (BARBOSA; JOFILI, 2004; ZOMPERO; LABURU, 2010).

Após a conclusão das caixas entomológicas, os alunos fizeram avaliações teóricas e práticas sobre o referido tema e os resultados foram satisfatórios nas três turmas envolvidas. Nenhum aluno necessitou passar por um processo de recuperação de conhecimentos não assimilados ou trabalhos extraclasses e acompanhamento individual. A ausência de revisão de conteúdos na disciplina ministrada indica que as práticas a campo e laboratório tiveram aceitação por parte dos alunos e demonstram a eficiência do ensino e aprendizagem.

De acordo com Guimarães-Brasil et al., (2017), a ausência de intervenções pedagógicas evidencia que a confecção de caixas entomológicas pelos alunos não apenas teve aceitação por parte deles, mas, sobretudo, indica sua eficácia ao ensinoaprendizagem. Além de ser um importante recurso didático para o ensino das disciplinas de Entomologia Agrícola e manejo de pragas, pois, além de constituir um material de baixo custo, teve a potencialidade de tornar as aulas mais atraentes aos 
educandos e, assim, tornar o aprendizado mais eficiente.

A coleção com 1203 insetos, (mais detalhes podem ser observados na tabela 1), permanecerá armazenada no laboratório e servirá como recurso didático a ser utilizado em aulas práticas nas disciplinas de fitossanidade e culturas anuais de inverno e verão dos cursos técnicos em Agropecuária e como disciplinas de base comum do curso de Agronomia. Além disso, ela deve servir como material de pesquisa para estudantes e a comunidade local. Conforme salienta Moya (1998), o ato de colecionar é considerado um comportamento universal do ser humano, visando perpetuar sua imagem, afirmar a posse de bens, obter o reconhecimento de seu meio e classificar o mundo a sua volta.

A confecção de uma coleção entomológica apresenta-se como uma eficiente estratégia de aprendizagem nas escolas profissionalizantes, permitindo melhor aproveitamento das aulas por meio do contato teórico-prático com o conteúdo abordado como também tem despertado a percepção entomológica dos escolares envolvidos na atividade. Ademais, uma coleção entomológica pode ser inserida em diversas outras atividades educacionais da escola, podendo ser um importante recurso didáticopedagógico nas aulas de Biologia (GUIMARAES-BRASIL et al., 2017) e Agronomia.

É possível perceber que a coleção entomológica possui grande potencial como material didático, visto que os alunos ampliaram consideravelmente sua aprendizagem após a utilização da ferramenta em sala de aula, demonstrando que a interação com o material prático facilita a identificação, diferenciação e morfologia, potencializando a consolidação do conhecimento (MOURA et al., 2020).

Ainda é importante ressaltar o significado pessoal que a atividade teve para os alunos, para muitos deles deixar uma contribuição de tamanha representatividade para a instituição chamou-os à responsabilidade de ter deixado um legado para toda comunidade acadêmica, deixado semeada, ainda que de forma basal, a sementinha da importância da pesquisa para a vida e realização profissional de cada um.

TABELA 1. Ordens, número de insetos, famílias e porcentagem de cada ordem na coleção entomológica do Laboratório de Fitossanidade - IFRS Campus Vacaria, (2020).

\begin{tabular}{|c|c|c|c|}
\hline Ordens & $\begin{array}{c}\text { No de } \\
\text { Insetos }\end{array}$ & Famílias & $\begin{array}{c}\text { \% de cada } \\
\text { Ordem }\end{array}$ \\
\hline Coleoptera & 648 & $\begin{array}{c}\text { Scarabaeidae, Curculionidae, Silphidae, } \\
\text { Carambycidae, Lycidae, Elateridae, } \\
\text { Cantharidae, Carabidae, Silphidae, } \\
\text { Tenebrionidae, Erotylidae e Lampyridae }\end{array}$ & 53,86 \\
\hline Dermaptera & 36 & Forficulidae & 2,99 \\
\hline & & Hereronemiidae & 0,17 \\
\hline Phasmatodea & 2 & Blatiidae e Blaberidae & 2,82 \\
\hline & & Cercopidae, Aphrophoridae, & \\
\hline Blatodea & 34 & Pentatomidae, Aethalionidae, & 9,89 \\
\hline Hemiptera & 119 & &
\end{tabular}




\begin{tabular}{|c|c|c|c|}
\hline & & Reduviidae e Pyrrhorocidae & \\
\hline Diptera & 51 & Muscidae, Tabanidae e Sarcophagidae & 4,24 \\
\hline Orthoptera & 43 & Romaleidae, Tettigoniidae e Gryliidae & 3,57 \\
\hline Hymenoptera & 130 & $\begin{array}{c}\text { Formicidae, Ichneumonidae, Apidae e } \\
\text { Vespidae }\end{array}$ & 10,80 \\
\hline Mantodea & 11 & Acanthopidae & 0,92 \\
\hline Lepidoptera & 103 & $\begin{array}{c}\text { Hesperidae, Pieridae, Papilionidae, } \\
\text { Erebidae, Nymphalidae, Sphingidae, } \\
\text { Saturniidae }\end{array}$ & 8,56 \\
\hline Neuroptera & 5 & Crysopidae & 0,42 \\
\hline Odonata & 21 & Aeshnidae & 1,75 \\
\hline
\end{tabular}

Fonte: Laboratório de Fitossanidade - Labfito.

\section{CONCLUSÃO}

Por meio deste estudo, concluiu-se que trabalhar de forma colaborativa, atrelando a teoria e a prática tem proporcionado aos alunos e professores resultados positivos no processo de ensino e aprendizagem. Oportuniza ao aluno aprimorar seus conhecimentos, o que acrescenta melhor percepção de mundo, bem como coloca o aluno numa posição em que abre caminhos para aprimorar sua interação com o grupo, o que possibilita uma maior abertura para expandir suas relações sociais.

A iniciativa e aplicabilidade da coleção didática de insetos como ferramenta pedagógica possibilitou aos alunos associar seus conhecimentos cotidianos e científicos, propiciando momentos de questionamentos e trocas de experiências referentes aos insetos. Esse processo leva o aluno a quebrar tabus, construir uma nova forma de pensar e agir referente ao meio ambiente.

Também se faz necessário ressaltar que a coleção é uma ferramenta pedagógica pertencente à instituição de ensino, dessa forma, podendo auxiliar professores de diferentes áreas, tornando também possível a realização de um trabalho multidisciplinar, envolvendo diferentes turma e professores.

Essa iniciativa, ademais, proporciona diálogo, trocas de saberes e contribui para abertura do espaço acadêmico à comunidade, uma vez que a instituição de ensino presta serviço à comunidade por meio de pesquisa, ensino e extensão.

Por fim, sabe-se que a ação docente realizada de forma responsável é um desafio, bem como a adesão a diferentes metodologias a materiais didáticos, desperta, por vez, desconforto e insegurança por parte tanto dos docentes como dos alunos. É um desafio diário que se deve superar, respeitando nossos limites e desafiando professores e desafiando nossos alunos a cada dia. 


\section{REFERÊNCIAS}

ALBUQUERQUE, F. P.; MILLÉO, J.; LIMA, J. M. M.; BARBOLA, F. I. Entomologia no ensino médio técnico agrícola: Uma proposta de trabalho. Revista Eletrônica de Educação. v. 8, n. 3, p. 251-265, 2014. Disponível em: $<$ https://doi.org/10.14244/198271991030>.

AZEVEDO, H. J. C. C.; FIGUEIRÓ, R.; ALVES, D. R.; VIEIRA, V.; SENNA, A. R. O uso de coleções zoológicas como ferramenta didática no ensino superior: um relato de caso. Revista Práxis. v. 4, n. 7, p. 43-48, 2012. <https://doi.org/10.25119/praxis-4-7-548>.

BARBOSA, R. M. N.; JOFILI, Z. M. S. Aprendizagem cooperativa e ensino de química: parceria que dá certo. Ciência e Educação. v. 10, n. 1, p. 55-61, 2004. <https://doi.org/10.1590/S1516-73132004000100004>.

BRASIL. Ministério da Educação. Parâmetros curriculares nacionais: temas transversais - meio ambiente. Brasília- DF: MEC/SEF. 1998. URL: $<$ https://cptstatic.s3.amazonaws.com/pdf/cpt/pcn/volume-10-4-temas-transversais-meioambiente.pdf> Acessado em: 16 jan. 2021.

CAMARGO, A. J. A.; OLIVEIRA, C. M.; FRIZZAS, M. R.; SONODA, K. C., CORRÊA, D. C. V. Coleções entomológicas: legislação brasileira, coleta, curadoria e taxonomias para as principais ordens. Brasília (DF) Embrapa: 2015. 118 p. URL: <https://ainfo.cnptia.embrapa.br/digital/bitstream/item/122542/1/amabilio-01.pdf>

GODOTTI, M.; ROMÃO, J. E. Escola cidadã. A hora da sociedade. In: Salto para o Futuro: Construindo a escola cidadã, projeto político-pedagógico. Brasília: Ministério da Educação e do Desporto, SEED. 1998. URL: <http://www.dominiopublico.gov.br/download/texto/me002687.pdf>.

GUIMARAES-BRASIL, M. O.; SALES, F. A. L.; SOUZA, E. A.; CRUZ, C. E. F.; BRASIL, D. F. Construção de caixas entomológicas como ferramenta ao ensino-aprendizagem em cursos técnicos de agrárias. Holos. v. 33, n. 01, p. 21-30, 2017. <https://doi.org/10.15628/holos.2017.4393>.

GULLAN, P. J.; CRANSTON. P. S. The, insects: an outline of entomology. 4th ed.; Wiley: Hoboken, NJ, USA 2010. URL: <https://www.pdfdrive.com/the-insects-an-outlineof-entomology-d175584256.html>.

JURBERG, C. Bibliografia de Jocélia Grazia. Entomología y Vectores. v. 12, n. 1, p. 01-18, 2005. <https://doi.org/10.1590/S0328-03812005000100001>.

KRASILCHIK M. Práticas de Ensino de Biologia. (4 ${ }^{a}$ ed.). São Paulo: Editora da Universidade de São Paulo. 2005.

MATOS, C. H. C.; OLIVEIRA, C. R.F.; SANTOS, M. P. F.; FERRAZ, C. S. Utilização de modelos didáticos no ensino de entomologia. Revista de Biologia e Ciências da Terra. $\begin{array}{lllllll}\text { v. } & 9, & \text { n. } & 1, & \text { p. } & 19-23, & \text { 2009: }\end{array}$ 
<http://joaootavio.com.br/bioterra/workspace/uploads/artigos/3matos-

1816c32b2719.pdf>

MORAN, J. M. A educação que desejamos: novos desafios e como chegar lá. In: Como utilizar as tecnologias nas escolas. Campinas (SP): Papirus (Ed.). 2000. p. 101-111.

URL:

$<$ https://books.google.com.br/books?id=PiZe8ahPcD8C\&printsec=frontcover\&hl=pt-

$\mathrm{BR} \# \mathrm{v}=$ onepage $\& \mathrm{q} \& \mathrm{f}=\mathrm{false}>$.

MOREIRA, M. A. Aprendizagem significativa. Brasília: Editora UnB. 1999.

MOURA, P. D. C.; BEZERRA, M. S.; BRASIL, D. F.; GUIMARÃES-BRASIL, M. O. Coleção de abelhas como ferramenta didática facilitadora para a aprendizagem no ensino técnico. Holos; v. 36, n. 2, p. 01-09, 2020. $<$ https://doi.org/10.15628/holos.2020.8398>.

MOYA, M. C. H. Las Coleciones en un Museo Interactivo. In Cómo Hacer un Museo de Ciencias. Ediciones Científicas Universitarias: 1998. p. 59-67.

SANTOS, D. C. J.; SOUTO, L. S. Coleção entomológica como ferramenta facilitadora para a aprendizagem de ciências no ensino fundamental. Scientia Plena. v.7, n. 5, p. 01-08, 2011. URL: <https://www.scientiaplena.org.br/sp/article/view/310/186>.

SENICIATO, T.; CAVASSAN, O. Aulas de campo em ambientes naturais e aprendizagem em ciências: um estudo com alunos do ensino fundamental. Ciências e Educação. v. 10, n. 1, p. 133-147, 2004. <https://doi.org/10.1590/S151673132004000100010>.

SOUSA-LOPES, B. Sobre o uso de uma coleção entomológica como ferramenta didática no ensino médio noturno e a percepção de fatores que influenciam o baixo rendimento escolar. Experiências em Ensino de Ciências. v. 12, n. 8, p. 250-260, 2017. URL: <https://if.ufmt.br/eenci/artigos/Artigo_ID449/v12_n8_a2017.pdf>.

ZOMPERO, A. F.; LABURU, C.; E. As atividades de investigação no ensino de ciências na perspectiva da teoria da aprendizagem significativa. Revista Electrónica de Investigación em Educación em Ciencias. v. 5 n. 2, p. 12-19, 2010. URL: $<$ http://ppct.caicyt.gov.ar/index.php/reiec/article/view/7445>. 